\title{
Functional foods and health claims: a public health policy perspective
}

\author{
Mark Lawrence ${ }^{1, *}$ and Mike Rayner ${ }^{2}$ \\ 'Visiting Research Fellow and ${ }^{2}$ Head: British Heart Foundation Health Promotion Research Group, \\ Division of Public Health and Primary Health Care, University of Oxford, Oxford, UK
}

Submitted 9 December 1997: Accepted 25 January 1998

\begin{abstract}
Abstroct
Objective: To propose a policy framework for the regulation of functional foods and health claims within a public health context.

Design: This article reviews the empirical evidence and public health principles associated with functional foods and health claims to analyse the issues, challenge the assumptions that have emerged and explore options for moving forward.

Setting: Functional foods and health claims are among the more controversial and complex issues being debated by food regulators internationally. Proponents of functional foods and health claims state that functional foods may reduce health care expenditure and health claims are a legitimate nutrition education tool that will help them inform consumers of the health benefits of certain food products. Conversely, opponents of these developments respond that it is the total diet that is important for health, not so-called 'magic bullets'. Moreover, they argue that health claims will enable manufacturers to indulge in marketing hyperbole and essentially blur the distinction between food and drugs. This topic provides a valuable case study of public policy in relation to food and health.

Conclusion: The need to maintain a general prohibition on health claims while accommodating specific exemptions supported by scientific substantiation is recommended. Nutrition education and monitoring and evaluation are integral to the proposed regulatory framework. The intention of this policy position is to encourage research and development of innovative food products while avoiding an inappropriate medicalization of the general food supply.
\end{abstract}

\author{
Korwords \\ Food regulotion \\ Health doims \\ Functional foods \\ Public hoalth policy
}

A fundamental public health nutrition principle is that it is the total diet, not individual food products that determine health. Conventional wisdom acknowledges that there is no such thing as a good or bad food, only good or bad diets. Terms such as balance, variety and moderation have become the common parlance of nutrition education.

Functional foods are a concept that some claim will represent a departure from the conventional relationship between food and health. Although the term functional food is commonly used and there is now a scientific journal dedicated to the subject ${ }^{\dagger}$, there remains a lack of consensus on a definition for the term and it is not recognized from a regulatory perspective. Functional foods are generally described as food products that may deliver a health benefit beyond providing nutrients $s^{1,2}$. Certain stakeholders are now suggesting that conventional wisdom should be amended, while there still may be no such thing as a

\footnotetext{
'The Journal of Nutraceuticles, Functional and Medicinal Foods, first published in 1997.
}

bad food, they suggest there may now be good foods. It is suggested that the health benefits of functional foods may be conferred by a variety of production and processing techniques, including fortifying certain food products with specific nutrients, phytochemicals or active microorganisms. It is also being suggested that with increased knowledge of the genetic basis of certain diseases and the genetic profile of individuals, it may be possible to construct functional foods tailored to individuals health needs ${ }^{3}$.

Certain food manufacturers, and to a lesser extent, some medical research scientists, are calling on food regulators to permit the use of health claims on food products. For the purpose of this paper we define a health claim as: 'Health claims means any representation that states, suggests or implies that a relationship exists between a food or a nutrient or other substances contained in a food and a disease or health-related condition.' This is the definition drawn up by the Codex Alimentarius Commission (Codex) ${ }^{4}$. The existence and promulgation of functional foods is contingent upon regulatory approval for the use of health claims. Food 
manufacturers state candidly that if they do not have the ability to promote the potential health benefits of their products to consumers, that research and development into functional foods is unlikely to proceed. In this context the push for functional foods and health claims may be regarded as a strategic 'agenda' to enable a specific form of development of the food supply by certain manufacturers.

Functional foods and health claims are among the most complex and controversial issues facing food regulators both nationally and internationally. The conceptual nature of functional foods and the prohibition on explicit health claims in most countries has resulted in a lack of information with which to make decisions. Stakeholders have tended to initiate and frame this public policy debate around opinions and speculation, rather than empirical evidence. The purpose of this article is to review the current developments, analyse the issues from both a theoretical and empirical perspective, challenge the assumptions that have emerged from the often adversarial debate between different stakeholders involved in these topics and explore options for moving forward.

\section{The state of play}

Food regulation policy in relation to health claims is now being reviewed in many countries. At its 24 th session the Food Labelling Committee of the Codex Alimentarius Commission, the international food standards agency, agreed that further discussion about health claims would be deferred so as not to compromise the progression of the Draft Guidelines for Use of Nutrition Claims 5 . With the adoption of these guidelines, Codex has now agreed to circulate proposed draft recommendations on health claims for comment ${ }^{6}$. While most countries do not permit the use of health claims (as defined above), in recent years several countries including the USA, South Africa and Japan have developed regulatory frameworks permitting certain claims to be made, albeit within strict guidelines.

The challenge confronting food regulators charged with formulating policy on this topic is the lack of available empirical evidence. Debate and decisionmaking associated with the functional foods/health claims agenda is frequently based on assumptions. This was the situation confronting the American Food and Drug Administration (FDA) in the preparation of its pioneering work associated with the American Nutrition Labeling and Education Act (NLEA). The FDA issued the final regulations implementing the NLEA in 1993 and this has resulted in extensive changes to food labelling in the USA, including permission for manufacturers to use model health claims for those food products which satisfy specified qualifying criteria ${ }^{7}$. An example of one such model health claim is, 'Low-fat diets rich in fiber-containing grain products, fruits, and vegetables may reduce the risk of some types of cancer, a disease associated with many factors.'

A critical component of the decision-making process associated with the passage of the NLEA was the publishing of a regulatory impact analysis in the form of an economic cost-benefit study. The FDA estimated that allowing manufacturers to make food label changes in response to the NLEA, particularly to place new nutrient content claims and health claims on product labels, would over a 20 -year period result in at least 12,600 lives saved and up to $\$ 21$ billion saved $^{8}$. This analysis was based upon a number of questionable assumptions, including that:

- consumers would read and understand nutrient content claims and health claims;

- consumers will then be motivated to change behaviour, and

- consumers will change behaviour.

This exercise represents a simplistic and unrealistically positive analysis of a complex public policy matter. The likelihood that there would be a significant impact on reducing mortality in the population would require all these assumptions to be met. However, preliminary research using focus group testing indicates that consumers are sceptical of health claims and feel 'bombarded' by diet and health information'. Different wordings and different presentation styles for improving the communication effectiveness of FDA-approved health claims has since been trial tested in consumer research by the $\mathrm{FDA}^{10}$. The results of this testing do not support the use of health claims as being an effective public health intervention to change people's food choices to achieve healthier diets.

In the absence of additional empirical evidence for planning the regulation of potential functional foods and health claims we explore possible policy options for their regulation by analysing the topic from a theoretical perspective. Firstly, we examine the 'performance' of the current food supply and the system within which it is regulated to assess the need for change. Secondly, we analyse the rationale to the functional foods/health claims agenda in accordance with objectives for the setting of food standards.

\section{Does the food supply and its public policy regulation need to be changed?}

\section{Is there a need to 'fix' the food supply?}

An implicit assumption of the functional foods/health claims agenda is that worldwide the food supply needs to be 'fixed' on public health grounds. It is a paradox 
that those countries most actively engaged in the functional foods/health claims debate have a historically unprecedented quantity and quality of food currently available to promote public health. In most developed countries there are few inherent nutrient deficiencies in the food supply. While national dietary surveys often do reveal that there may be inadequacies or dietary imbalances among individuals or subgroups within the population, generally, these dietary problems are associated with underlying socioeconomic circumstances. In this context, functional foods represent a form of technological intervention that may 'treat' the immediate symptom without addressing the underlying cause. This form of solution is nonsustainable as the cause remains and a reliance may be created on ongoing treatment rather than prevention.

In developing countries, while there may be problems with the food supply, the limitations of functional foods as a potential solution are more stark than in developed countries. The food and nutrition challenges are embedded in chronic shortages of safe, sufficient and suitable food principally resulting from economic and environmental problems. These fundamental deficiencies are unlikely to be ameliorated simply by the existence of sophisticated value added food products.

\section{Is the conventional food regulatory policy 'broken'?}

The conventional food regulatory policy in relation to health claims has been criticized by some stakeholders as being both 'old and outdated' and discouraging research and development opportunities and not being able to prevent abuse. However, the conventional policy adopted in most countries is based on the fundamental scientific principle that it is the total diet, not individual foods, that determine health outcomes. This principle is as relevant today as when the policy was first developed.

While the majority of food manufacturers abide by regulations associated with health claims, research in Australia ${ }^{11}$ and the $\mathrm{UK}^{12}$ has identified a significant level of contravention. It may be that there is not an inherent problem with the policy position as such, rather there is a need to strengthen enforcement capabilities and tighten loopholes that are fostering misinterpretation of the intent of the policy position.

Food manufacturers are able to take advantage of many opportunities to incorporate nutrition information on their food labels and in advertising. For example, Codex and most countries have regulations permitting the use of nutrient content claims on food labels to describe the level of a nutrient contained in a food, e.g. 'low fat', or 'source' of a vitamin ${ }^{5}$. In addition, food manufacturers are normally allowed to use nutrient function claims which describe the physiological role of the nutrient in growth, development and normal functions of the body, e.g. 'Contains folic acid: folic acid contributes to the normal growth of the fetus's. Difficulty arises when it is not clear whether a claim may be an illegal health claim or a legal nutrient function claim. This is more an issue of interpretation of the regulation, rather than a flaw in the logic to the regulations and there is a need for food regulators to clarify permissible nutrient function claims.

Public health and consumer associations are asking why the converse of the current agenda to permit health claims on food products cannot be explored with equal tenacity ${ }^{13,14}$. Specifically, whereas the manufacturers of certain food products may be permitted to make dietary guideline-type claims, as represented by the model NLEA claims, then it is suggested that there should be a requirement for manufacturers to include 'health warnings' on product labels where there is evidence that a product may be inconsistent with dietary guideline recommendations. An example of a health warning being proposed is: 'this is a high sugar food, high sugar foods eaten frequently cause tooth decay'.

\section{The functional foods/health claims agenda and food standards objectives}

\section{Will functional foods/bealtb claims promote/ compromise public bealth?}

Public health is characterized by a focus on populations. Generally, interventions designed to promote public health may be categorized into two health paradigms: those that aim to address the underlying determinants of health in populations as a whole, and those that aim to modify dietary behaviour and reduce the level of risk factors in individuals.

The most powerful determinants of the health of populations are the social, economic and cultural circumstances in which people live ${ }^{15}$. Populations with lower socioeconomic status suffer a disproportionate burden of ill-health and disease. Interventions directed at promoting the health of populations need to address the underlying social, economic and cultural circumstances in which health is created. Interventions also need to preserve the integrity of environmental resources, including the food supply, that are essential for health ${ }^{16}$.

Interventions directed at preventing life-style-related disease in individuals generally aim to address the risk factors associated with disease, by changing relevant behaviours, including dietary behaviour. In this context in particular, food is regarded as a commodity that is modified to assist the dietary reform process.

The rationale to and the purpose of interventions within each of these two paradigms are quite distinct and it is important to keep expectations of their impact 
on public health in perspective. Moreover, the appropriateness of interpreting and applying the findings of clinical research to generate public health policy is unclear because clinical research is generally designed to investigate the effectiveness of interventions aimed at individuals not populations. This provides a salutary lesson for expectations associated with the functional foods/health claims agenda.

The scientific evidence to substantiate the claimed physiological action(s) of potential functional foods will generally be derived from clinical research trials. However, the results of such trials cannot be expected necessarily to translate to the 'real world' where freeliving people, may have different age, sex, cultural and life-style behaviour patterns which may interfere with the variables investigated. Essentially, sophisticated food technologies are used to produce functional food products in accordance with findings from medical research. In this context, functional foods are a form of 'technological intervention', 17 . It is unreasonable to expect technological interventions to 'solve' complex social problems. Instead, it may be more appropriate to place expectations regarding functional foods and health claims within the context from which they were developed, i.e. potential impacts in certain individuals.

For example, psyllium is a very rich source of soluble fibre and has been included as an ingredient in a breakfast cereal. Feeding trials have indicated that a psyllium-based breakfast cereal reduced cholesterol levels by approximately $9 \%$ when consumed as part of a low-fat diet ${ }^{18,19}$. The manufacturer of the breakfast cereal urged the FDA to consider the following health claim for psyllium and coronary heart disease ${ }^{20}$ : 'Lowfat diets that include foods high in soluble fiber from psyllium may help lower blood cholesterol levels, which are among the risk factors for heart disease.'

There are two questions relevant to translating the scientific data into a health claim:

- How relevant are the findings to the majority of the population? The feeding trials involved middle-aged men who were hypercholesterolaemic. Is it appropriate to extrapolate these findings to men who are not hypercholesterolaemic, to women, to children?

- Are there special considerations that need to be taken into account? The studies reported that between 3 and 5 servings per day of the breakfast cereal were required to achieve the $9 \%$ reduction in cholesterol levels.

The nature and scope of a potential health claim must be consistent with the scientific data and the paradigm within which research was conducted. In the case of psyllium, as one study concluded, 'a psyllium enriched breakfast cereal is a useful adjunct to the dietary management of hypercholesterolaemia' ${ }^{21}$. In this context a health claim targeted to specific individuals may be warranted, however, it is not clear how a health claim relevant to the population as a whole could be justified.

There are many aspects of the relationship between food and health that remain unknown. The relationship is complex and it is often premature to assume that full account can be taken of the public health impact of novel changes in the composition of foods. The reduction of nutritional analysis to single foods, or nutrients, and single health outcomes is problematic as the introduction of one intervention can create broader and more profound impacts particularly in distorting nutrient metabolism. For example, the interaction between nutrients may affect their bioavailability, as occurs with the interference between excessive calcium intake and iron absorption ${ }^{22}$.

\section{Moving forward: a potential regulatory framework}

\section{A nutrition information food standard}

It is suggested that the regulation of potential functional foods and health claims be addressed within a framework that comprehensively encompasses the scope of nutrition information on the food label. Specifically, a separate food standard could be established to facilitate the use of the food label as a vehicle to inform the consumer of both the ingredient and nutrient content of a food and the relationship between food and health.

A conceptual framework of the continuum of potential nutrition information on food labels has been adapted from a previous concept paper on this topic $^{17}$ and is outlined in Table 1 . The intention of this framework is to illustrate the relationship between the different types of potential nutrition information that may appear on food labels and to suggest where claims for functional foods may fit within the health claims context.

The different claims are categorized in Table 1 on the basis of the relationship between nutrients or foods and health that they are describing. The health orientation of the claims shifts incrementally from the left to the right of the continuum from describing health relationships for the general population to disease prevention and treatment relationships for population subgroups and individuals. In parallel with this shift the degree of regulatory control over the potential claim increases. Therapeutic, or medicinal, claims are included within this framework to place the extreme of the continuum in perspective.

It is suggested that health claims be considered in two distinct contexts in accordance with the health outcome that they describe: 
Table 1 Conceptual framework for nutrition information on food labels ( $\mathbb{G}$ food-drug interface)

\begin{tabular}{|c|c|c|c|c|c|c|}
\hline & $\begin{array}{l}\text { Nutrient } \\
\text { content } \\
\text { claims }\end{array}$ & $\begin{array}{l}\text { Nutrient } \\
\text { function } \\
\text { claims }\end{array}$ & \multicolumn{2}{|c|}{ Health claims } & & $\begin{array}{l}\text { Therapeutic } \\
\text { (medicinal) } \\
\text { claims }\end{array}$ \\
\hline Definition & $\begin{array}{l}\text { A nutrition } \\
\text { claim that } \\
\text { describes the } \\
\text { level of a } \\
\text { nutrient } \\
\text { contained in a } \\
\text { food }\end{array}$ & $\begin{array}{l}\text { A claim that } \\
\text { describes the } \\
\text { physiological } \\
\text { role of the } \\
\text { nutrient in } \\
\text { growth, } \\
\text { development } \\
\text { and normal } \\
\text { functions of the } \\
\text { body }{ }^{6}\end{array}$ & \multicolumn{2}{|c|}{$\begin{array}{l}\text { Any representation that } \\
\text { states, suggests or } \\
\text { implies that a } \\
\text { relationship exists } \\
\text { between a food or a } \\
\text { nutrient or other } \\
\text { substances contained in } \\
\text { a food and a disease or } \\
\text { health-related } \\
\text { condition }\end{array}$} & 2 & $\begin{array}{l}\text { Based on the } \\
\text { relationship } \\
\text { between a drug } \\
\text { and the } \\
\text { prevention/ } \\
\text { treatment of a } \\
\text { disease }\end{array}$ \\
\hline $\begin{array}{l}\text { Target } \\
\text { group }\end{array}$ & $\begin{array}{l}\text { General } \\
\text { population }\end{array}$ & $\begin{array}{l}\text { General } \\
\text { population }\end{array}$ & $\begin{array}{l}\text { General } \\
\text { population } \\
\text { (dietary } \\
\text { guideline } \\
\text { claims) }\end{array}$ & $\begin{array}{l}\text { Subgroups } \\
\text { and } \\
\text { individuals } \\
\text { (functional } \\
\text { claims) }\end{array}$ & 2 & $\begin{array}{l}\text { Individuals with } \\
\text { a disease or an } \\
\text { abnormal } \\
\text { physiological } \\
\text { condition }\end{array}$ \\
\hline
\end{tabular}

- 'Dietary guideline' claims. These health claims are intended to reinforce dietary guideline messages. They relate a food, or nutrient in a food, to a dietary guideline recommendation. These claims are targeted at the general population. An example of this application is the NLEA approach permitting model health claims.

- 'Functional' claims. These health claims are intended to describe the influence of a food, or biologically active substance in a food, on a specific physiological process related to a disease or on a health outcome. These claims are targeted at population subgroups or individuals.

\section{Elements of a suggested public policy for bealtb claims}

From a public health perspective it is recommended that the current policy of a general prohibition on health claims in most countries be maintained to reflect the fundamental nature of the relationship between food and health. However, the policy should permit certain exemptions to this prohibition. Specifically, food regulators could permit dietary guideline claims and in certain cases functional claims. The former exemptions may support the promulgation of the dietary guideline recommendations among the population and the latter may offer benefits for certain individuals, particularly those with adequate resources and skills to incorporate potential functional food products appropriately into their diets.

With this policy principle in place, the main need for food regulators is to clarify provisions permitting certain health claim exemptions to the general prohibition. The following provisions are suggested.

\section{Scientific substantiation}

Scientific substantiation will be central to the approval of specific exemptions to the general prohibition on health claims. It has been described ${ }^{23}$ as essential to demonstrate:

- that the food (or components) in question will cause a significant physiological benefit when consumed by a person as part of a normal diet,

- that a beneficial effect can be achieved by consuming a reasonable amount of the food on a regular basis, - the minimum or maximum amount and the frequency of consumption required to achieve an effect, - that the beneficial effect is maintained over a reasonable period of time, and is not a short-term response to which the body adjusts,

- who may benefit from the effect, e.g. whether this is the entire population, at risk groups or individuals with a disease, and

- how the effect is brought about, although the exact biological mechanism(s) may not be fully understood.

The substantiation for dietary guideline claims has effectively been established in the process of developing dietary guideline recommendations. It is anticipated that the evidence for substantiating functional claims generally will be driven by medical research findings and would need to be assessed on a case-bycase basis. It may be desirable to approve a licence of exclusivity over specific claims to protect the investment of certain manufacturers in researching and developing innovative products. Alternatively, there may be circumstances where the need for such claims is initiated by special government policy. For example, to encourage folate fortification of staple foods as an intervention to prevent neural tube defects ${ }^{24}$.

Governments have effectively sanctioned the development of functional foods when they are promoting 
folate fortification as an intervention to increase the folate intake of target individuals and thereby prevent a specific disease outcome. The necessary substantiation required for a functional claim to be made has been implicitly condoned within the policy development process. The use of a health claim to complement this intervention could have the benefit of informing the target individuals of the benefit of consuming fortified products and informing other individuals who may wish to avoid such products ${ }^{25}$.

It has been suggested that systematic review of the scientific data should be used to assess the validity of health claims ${ }^{26}$. While systematic review has become an established method for assessing the evidence for the effectiveness of medical interventions, it has not hitherto been used in assessing the validity of potential health claims. A systematic review aims to ensure that all the scientific evidence is considered and that studies included meet defined standards of methodological quality.

In its major review of the NLEA, the Keystone report ${ }^{27}$ identified that the scientific evidence may be drawn from three general types of data:

- epidemiological data (derived from studies of population or groups assessing associations between food substances and disease),

- data on biological mechanisms (derived from chemical, cellular or animal models investigating plausible mechanisms of action), and

- data from intervention trials (derived from controlled intervention trials of human subjects).

A hierarchy of evidence amongst experimental studies ranging from randomized controlled trials to descriptive studies has been suggested to identify the most reliable and valid studies ${ }^{20}$. It is suggested that data from chemical, cellular or animal experiments should only be used to provide supporting evidence. Good quality intervention trials need to be of sufficient duration, size and as ecologically valid as possible, i.e. generalizable to free-living populations eating reasonable amounts of food at reasonable frequency ${ }^{27}$.

Criteria for evaluating the validity of data and the quality of studies as part of a systematic review of studies for drawing conclusions about cause and effect have been suggested by Susser ${ }^{29}$, Bradford Hill ${ }^{30}$ and Ink and Shinnick ${ }^{23}$. The following criteria are distilled from these sources:

- Consistency. The observed association should have been observed more than once by different persons, in different places, under different circumstances and at different times.

- Strength and quality. The study design needs to be appropriate for exploring the asserted relationship and the results must be statistically significant.
- Biological plausibility. The relationship should be supported by a mechanistic theory which fits in with wider physiological and biochemical dogma.

- Demonstrate an effective dose (a dose-response relationship has been recommended for drug trials but this criteria may be unrealistic in a food context).

- Show a temporal relationship. Interventions should be followed by health outcomes not vice versa.

- Specific. A variable should predict the occurrence of another with precision.

Once the systematic review has been completed there will be a need to make judgements, based on the deliberative evaluation of all existing data, on whether to authorize a health claim. The NLEA has provided a model for this process which specifies seeking significant scientific agreement among independent and expert scientists ${ }^{27}$. This procedure could be subjected to the 'judicial principle' which provides a practical approach to decision making where absolute proof may not be available but there is sufficient evidence to commit a jury to take action ${ }^{31}$. The nature and extent of the scientific evidence required must be determined on a case-by-case basis.

\section{The food product}

The rationale to health claims is that they will promote the selection of certain food products to benefit nutritional health outcomes. As such it is important that the food products on which potential health claims may appear reflect the public health intent of this intervention and do not compromise broader public health outcomes. Certain safety and compositional criteria need to be met for a food product to qualify for a health claim. Specifically, the food must:

- make a significant contribution to the nutritional composition of the diet,

- not contain certain excess (disqualifying) levels of nutrients that may be inconsistent with the dietary guidelines,

- not be toxic or cause allergic reactions at high consumption levels or adversely displace other foods in the diet, and

- contain the active biological substance in a viable form, especially in relation to microorganisms, and there should be a sufficient amount in a reasonable quantity of the food.

\section{The claim}

A potential health claim on a food product must accurately convey the science resulting from the substantiation process. As such, it needs to:

- convey the relationship of the food to the total diet,

- be consistent with the nature and scope of the 
research, if the data are collected from a representative cross-section of the population, then the claimed benefit can extend to the whole population. Alternatively, if the data are collected from a specific target group, then the claim should only refer to a benefit for this target group,

- be complete and understandable to consumers,

- be qualified with a warning statement where appropriate, e.g. about potential allergens or intolerance factors, and

- be qualified with a statement of intended use where appropriate, e.g. level and frequency of consumption required for a health effect.

\section{Complementary initiatives}

Integral to the development of a comprehensive nutrition information standard is the need to ensure that adequate and timely resources are made available for initiatives to complement the implementation of the standard and to protect public health and safety.

Health claims are not a panacea to promote consumer understanding of the relationship between food and health. The food label is essentially one tool that can complement broader nutrition education initiatives. It would be simplistic to assume that providing more information will necessarily help. While some consumers may assiduously read food labels, others are clearly overwhelmed when confronted with the bewildering array of messages, often couched in technical language. The NLEA has addressed the issue of health claims as just one component of an integrated and comprehensive nutrition education strategy ${ }^{32}$. It is within this broader context that health claims may have a role.

One purpose of nutrition education is to place nutrition information in a meaningful context. Armed with sound nutrition principles, consumers will be better placed to navigate their way through the myriad of messages and cacophony of claims that already exist in the marketplace ${ }^{33}$. Consumers need to be given the opportunity to make informed decisions regarding potential health claims associated with individual food products and educated about how these products might best be accommodated within their overall diets.

From a public policy perspective, there is a clear need for a monitoring and evaluation mechanism that can collect and analyse data in a timely and comprehensive way to inform future decision making. Conventional risk assessment procedures for novel ingredients and products are generally limited to short time frames and to considering the ingredient or product in isolation. Information on both consumer awareness and understanding of potential health claims and functional food products, and of their broader public health impact alone and in combination with other foods and over both short and extended time periods, is required.

\section{Conclusion}

The functional foods/health claims agenda forces food regulators to establish a regulatory regime that will provide food manufacturers with a secure framework for their product research, development and marketing, while upholding the protection of public health and safety. How the relationship between food and public health is defined and who is best placed to inform consumers have become the moral grounds over which the functional foods/health claims agenda has been framed. Currently there is a lack of both empirical and theoretical evidence to sustain an argument that functional foods and health claims will either promote or harm public health.

At a technical level the debate concerns the appropriateness of extrapolating the limited available data, derived predominantly from clinical studies on individuals, to change public health policy intended for the population as a whole. It may be unreasonable to expect that interventions targeted at an individual's dietary intake can affect population-wide health objectives. Here the need is to ensure that if food is constructed as a form of technological intervention, expectations about its potential impact on public health must be kept in perspective. This in turn raises questions about the nature of scientific data to generate or change public health policy, the quantity and quality of scientific evidence necessary for evidence-based decision making, and the context within which potential claims should be based. As such, the functional foods/health claims agenda provides a valuable case study of the public policy process in relation to food and health.

Our analysis accepts that there may be potential for certain medical benefits in which food products may approach the action of drugs for specific individuals. Regulatory change could be set in a context of offering individuals more choice to construct a diet consistent with medical advice and to assist at-risk individuals to reduce risk factors and help prevent disease. From a public health perspective it is recommended that the policy of a general prohibition on health claims be maintained to reflect the fundamental nature of the relationship between food and health. However, the policy should permit certain exemptions to this prohibition to accommodate the potential for food manufacturers to formulate products that are taking advantage of the data emerging from scientific studies. There may be potential benefits for certain individuals, particularly those with adequate resources and skills to incorporate potential functional food products appropriately into their diets. In this context the main need is for food regulators to clarify provisions permitting certain health claim exemptions to the general prohibition. 
It is intended that this policy position will prevent a general 'medicalization' of the food supply, i.e. preventing the marketing and promotion of food as a form of drug, while enabling innovative food product research and development to be pursued.

\section{Acknowledgements}

Mark Lawrence was supported by a scholarship from the Public Health Research and Development Committee of the National Health and Medical Research Council (Australia). His research at the University of Oxford was approved as part of his PhD studies at Deakin University. Mike Rayner was supported by a grant from the British Heart Foundation.

\section{References}

1 National Food Authority. Discussion Paper on Functional Foods. Canberra: AGPS, 1994

2 American Dietetic Association. Position Statement of the American Dietetic Association: Pbytochemicals and Functional Foods. American Dietetic Association, 1994.

3 Committee on Opportunities in the Nutrition and Food Sciences, Food and Nutrition Board, Institute of Medicine. In Thomas PR, Earl, R, eds Opportunities in the Nutrition and Food Sciences, Research Challenges and the Next Generation of Investigators. Washington, DC: National Academy Press, 1994.

4 Codex Alimentarius Commission. Appendix 1: Draft Guidelines for use of Health and Nutrition Claims. Food and Agriculture Organization of the United Nations, World Health Organization, CL 1995/26-FL, 1995.

5 Codex Alimentarius Commission. Report of the 24th Session of the Codex Committee on Food Labelling, Ottawa, Canada, 14-17 May 1996. Food and Agriculture Organization of the United Nations, World Health Organization, ALINORM 97/22, 1996.

6 Codex Alimentarius Commission. Executive Committee Report, June 1997. Food and Agriculture Organization of the United Nations, World Health Organization, 1997.

7 US Department of Health and Human Services. Food and Drug Administration, Final Rules to Amend the Food Labeling Regulations. Federal Register 1993; 58: 2533-620.

8 US Department of Health and Human Services. Food and Drug Administration, Regulatory Impact Analysis of the Final Rules to Amend the Food Labeling Regulations, Federal Register 1993; 58: 2927-41.

9 Levy AS. Summary report on health claims focus groups. In: Final Report of the Keystone National Policy Dialogue on Food, Nutrition and Healtb. Colorado and Washington DC: Keystone Center, 1996.

10 Levy AS, Derby BM, Roe BE. Consumer Impacts of Health Claims: an Experimental Study US Food and Drug Administration. Center for Food Safety and Applied Nutrition, 1997.

11 Kneale C, Truswell AS. Health Claims: an Exploration of the Current Debate in Australia. The University of Sydney Nutrition Research Foundation, 1997.
12 Bradbury J, Lobstein T, Lund V. Functional Foods Examined London: The Food Commission, 1996.

13 Public Health Association (Australia). Submission to P153the Review of Health and Related Claims. The Australia/New Zealand Food Authority, 1997.

14 Australian Consumers Association. Submission to P153 - the Review of Health and Related Claims. The Australia/New Zealand Food Authority, 1997.

15 Blane D, Brunner E, Wilkinson RG, eds. Health and Social Organization: Towards a Health Policy for the 21st Century. London: Routledge, 1996.

16 World Health Organization, Ottawa Chaner for Health Promotion. Geneva: WHO, 1986.

17 National Food Authority. Review of the Food Standards Code: Concept Paper on Health and Related Claims. Canberra: AGPS, 1996.

18 Anderson $\mathrm{JW}$, Zettwoch $\mathrm{N}$, Feldman $\mathrm{T}$, Tietyen-Clark J, Oeltgen P, Bishop CW. Cholesterol-lowering effects of psyllium hydrophilic mucilloid for hypercholesterolemic men. Arcb. Intern. Med. 1988; 148: 292-6.

19 Greenberg ER, Baron JA, Tosteson TD, et al. A clinical trial of antioxidant vitamins to prevent colo-rectal adenoma. $N$. Engl. J. Med. 1994; 331: 141-7.

20 Kellogg supplement comments target psyllium health claim Food Labeling News 1993; December 23: 20-1.

21 Roberts DCK, Truswell AS, Bencke A, Dewar HM, Farmakalidis $E$. The cholesterol lowering effect of a breakfast cereal containing psyllium fibre. Med.J. Australia 1994; 161: $660-4$.

22 Hallberg L, Rossander-Hulten L, Brune M, Gleenup A Inhibition of haem-iron absorption in man by calcium. $\mathrm{Br}$. J. Nutr. 1992; 69: 533-40.

23 Ink SL, Shinnick FL. Scientific data requirements for supporting health claims. In: Tillotson JE, ed. America's Food Health Messages and Claims. Boca Raton: CRC Press, 1993

24 US Department of Health and Human Services. Food and Drug Administration. Food Labeling; health claims and label statements; folate and neural tube defects, and food standards: amendments of standards of identity for enriched grain products to require addition of folic acid, Final Rules. Federal Register 1996; 61: 8749-807.

25 Lawrence M. Highlight interview. Food Australia 1997; 49 : 3.

26 Rayner M. Systematic review as a method for assessing the validity of health claims. J. Roy. Soc. Chem. in press.

27 Keystone Center. Final Report of the Keystone National Policy Dialogue on Food, Nutrition and Health. Colorado and Washington DC: Keystone Center, 1996.

28 NHS Centre for Reviews and Dissemination. Undertaking Systematic Reviews of Research on Effectiveness. CRD Guidelines for Those Camring out or Commissioning Reviews. York: CRD, 1996.

29 Susser M. Judgement and causal inference: criteria in epidemiologic studies. Am. J. Epidemiol. 1977; 105: 1-15.

30 Bradford Hill $\mathbf{A}$. The environment and disease: association or causation? J. Roy. Soc. Med. 1965; 58: 295-300.

31 Tones K. Editorial. Beyond the randomized controlled trial: a case for judicial review Health Educ. Res. 1997; 12: i-iv.

32 Kulakow N, Baggett $\mathrm{W}$, McNeal G. Putting the E into NLEA! Nutr. Today 1997; September/October: 37-40.

33 Lawrence M, Cumming F. Editorial. Aust. J. Nutr. Dietet 1997; $54: 1,3$. 